\title{
Visible and Near IR Spectra of Some Divalent Transition Metal Cupferron Complexes
}

\author{
A. H. Abou El Ela, F. M. Abdelkerim, H. F. Aly, and H. H. Afifi \\ Physics Department, National Research Centre, Cairo, Egypt
}

(Z. Naturforsch. 30 b, 215-218 [1975]; received November 15, 1974)

IR Spectra, Cupferron Complexes

\begin{abstract}
The visible and near IR spectra of the ammonium salt of cupferron and manganese, cobalt, nickel and copper divalent cupferrate complexes are investigated. New absorption bands observed are given and assigned using the Tanabe-Sugano diagrams. In the absorption spectra of the divalent transition metal cupferrates a characteristic shift in the maxima and minima appears. Solvent effects on this shift were investigated.
\end{abstract}

Cupferron is a well known chelating agent. The IS spectrum of cupferron was first reported by Piskorz et al. ${ }^{1}$ and recently Yoshimura et al. ${ }^{2}$ studied the UV and IR spectra of cupferron and neo-cupferron and assigned the different absorption bands detected. Very recently, the IR spectra of the ammonium salt of cupferron and some divalent transition cupferron complexes were reported ${ }^{3}$ and the different absorption bands observed were assigned. A tetrahedral crystal field structure for the divalent transition metal cupferrates was suggested, therefore, the UV absorption bands observed $^{4}$ were satisfactorily assigned and the excited electronic states corresponding to these bands were identified.

In the present work the visible and near IR spectra of cupferron and some divalent transition metal cupferron complexes are presented and discussed. The absorption bands observed in the region $400 \mathrm{~nm}-2000 \mathrm{~nm}$ are given and assigned and the electronic states are identified.

\section{Experimental}

All chemicals used were A. R. grade, B. D. H. Label. The ammonium salt of cupferrone was obtained from Hungary "Reanal" Finomvegyszergyar, Budapest. The different cupferrate complexes were prepared by the method described earlier ${ }^{3}$. Elemental chemical analysis ${ }^{3}$ for the metal complexes prepared gave a chemical composition of

Requests for reprints should be sent to Dr. Abd elfattah Hassan Aвоu El Ela, AL ALWIYAH POB 2153, Baghdad, Iraq.
$\mathrm{ML}_{2}$, where $\mathrm{M}$ stands for the metal $(\mathrm{Mn}, \mathrm{Co}, \mathrm{Ni}$ and $\mathrm{Cu})$ and $\mathrm{L}$ for the ligand $\left(\mathrm{C}_{6} \mathrm{H}_{5} \mathrm{O}_{2} \mathrm{~N}_{2}\right)$.

The visible and near IR measurements were carried out using a spectrophotometer Beckmann model 15800 DR monochromator.

\section{Results and Discussion}

The visible and near IR spectra of the ammonium salt of cupferron and its metal complexes with divalent manganese, cobalt, nickel and copper in various solvents: Methyl, ethyl, isopropyl alcohols and dioxane measured for small concentrations for which Lambert's law is obyed are given in Figs. 1-4. In Table I the wavelength and molar extinction coefficients of the absorption maxima and minima observed for the different complexes are tabulated. The obtained spectra of ammonium cupferron are characterized by three absorption bands. Two intense absorption bands were observed for different solvents near $733 \pm 32 \mathrm{~nm}$ and $1900 \pm 100 \mathrm{~nm}$. The $733 \pm 32 \mathrm{~nm}$ band shows a solvent effect, the absorption band maximum shifts to longer wavelengths and its intensity decreases as the solvent changes from methyl alcohol to dioxane, while the $1900 \mathrm{~nm}$ band maximum shifts to shorter wavelengths. The $n \rightarrow \pi^{*}$ transition bands of the nitroso group, which are observed in the nitroso-amine derivatives around $350 \mathrm{~nm}$ and in the monomer of C-nitroso compounds around $700 \mathrm{~nm}^{5}$ are responsible for the color of these compounds. According to the assumption of HASZELDINE et al. ${ }^{6}$ the $n \rightarrow \pi^{*}$ transition band, which originates from the excitation of a non-bonding electron of the nitrogen atom 
to the antibonding $\pi^{*}$-orbital could appear in the spectrum of $\mathrm{N}$-nitroso compounds near $700 \mathrm{~nm}$. However, Yoshimura ${ }^{2}$ reported that no absorption bands were observed near $700 \mathrm{~nm}$ in the spectrum of cupferron. The absorption band observed near $733 \mathrm{~nm}$ in the present work could be assigned to

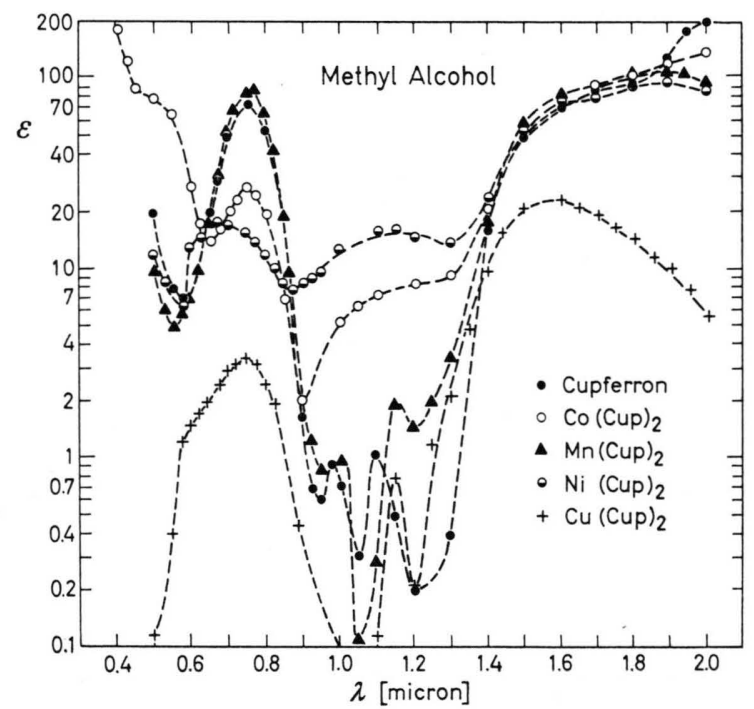

Fig. 1. Spectral dependence of the molar extinction coefficient of cupferrone and $\mathrm{Mn}, \mathrm{Co}, \mathrm{Ni}$ and $\mathrm{Cu}$ cupferrates, in methyl alcohol (conc. $10^{-2} \mathrm{~mole} / \mathrm{lit}$, $T=300^{\circ} \mathrm{K}$, cell thickness $1 \mathrm{~cm}$ ).

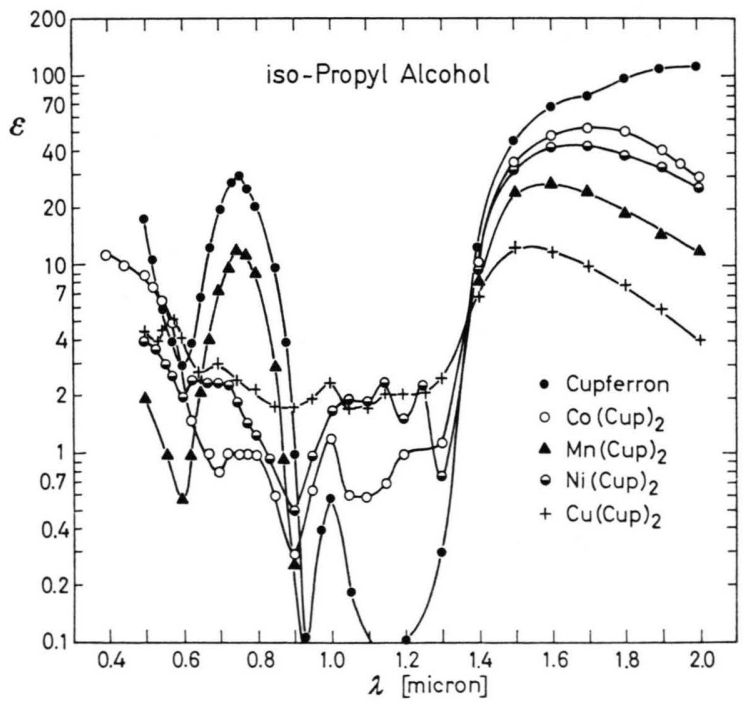

Fig. 3. Spectral dependence of the molar extinction coefficient of cupferrone and $\mathrm{Mn}, \mathrm{Co}, \mathrm{Ni}$ and $\mathrm{Cu}$ cupferrates, in isopropyl alcohol. $n \rightarrow \pi^{*}$ transition, while the shift resulting from solvent effect could be attributed to the effect of the polarity of the solvent on the transition. Further, the weak band appearing near $1000 \mathrm{~nm}$ could be ascribed to the effect of the interaction of cupferron and solvent on charge transfer bands.

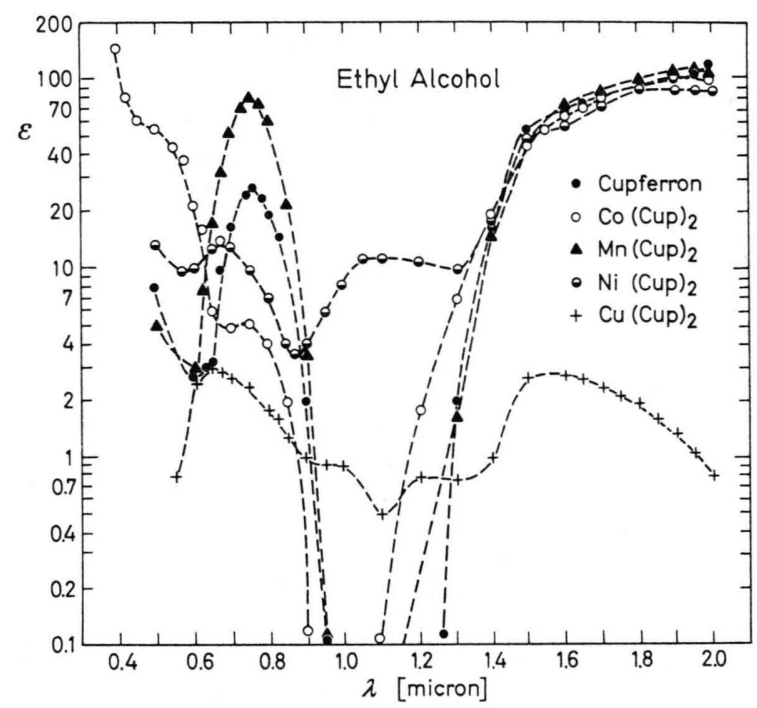

Fig. 2. Spectral dependence of the molar extinction coefficient of cupferrone and $\mathrm{Mn}, \mathrm{Co}, \mathrm{Ni}$ and $\mathrm{Cu}$ cupferrates, in ethyl alcohol.

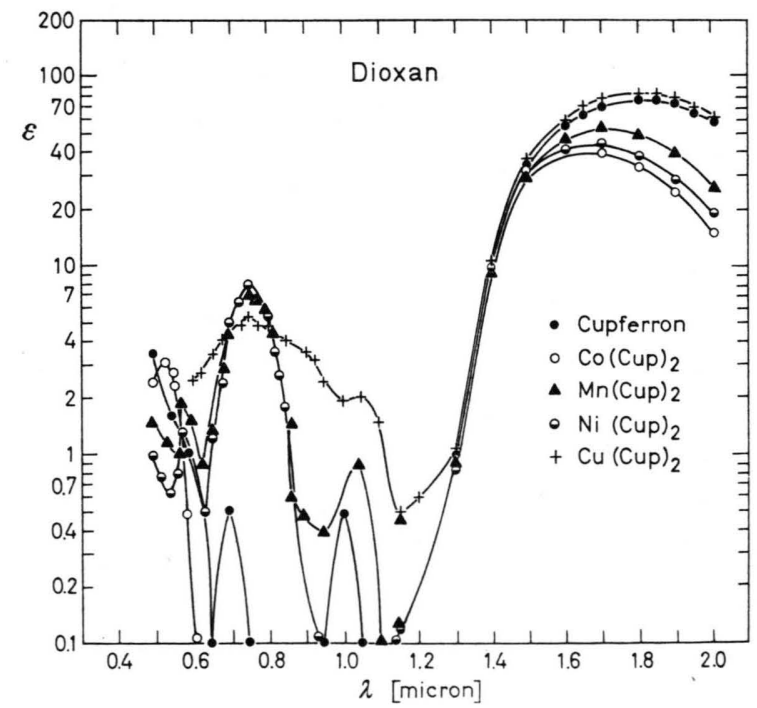

Fig. 4. Spectral dependence of the molar extinction coefficient of cupferrone and $\mathrm{Mn}, \mathrm{Co}, \mathrm{Ni}$ and $\mathrm{Cu}$ cupferrates, in dioxane. 
Table I. The molar extinction coefficient and the wavelengths of the absorption maxima for some divalent transition cupferron complexes in the visible and near IR region.

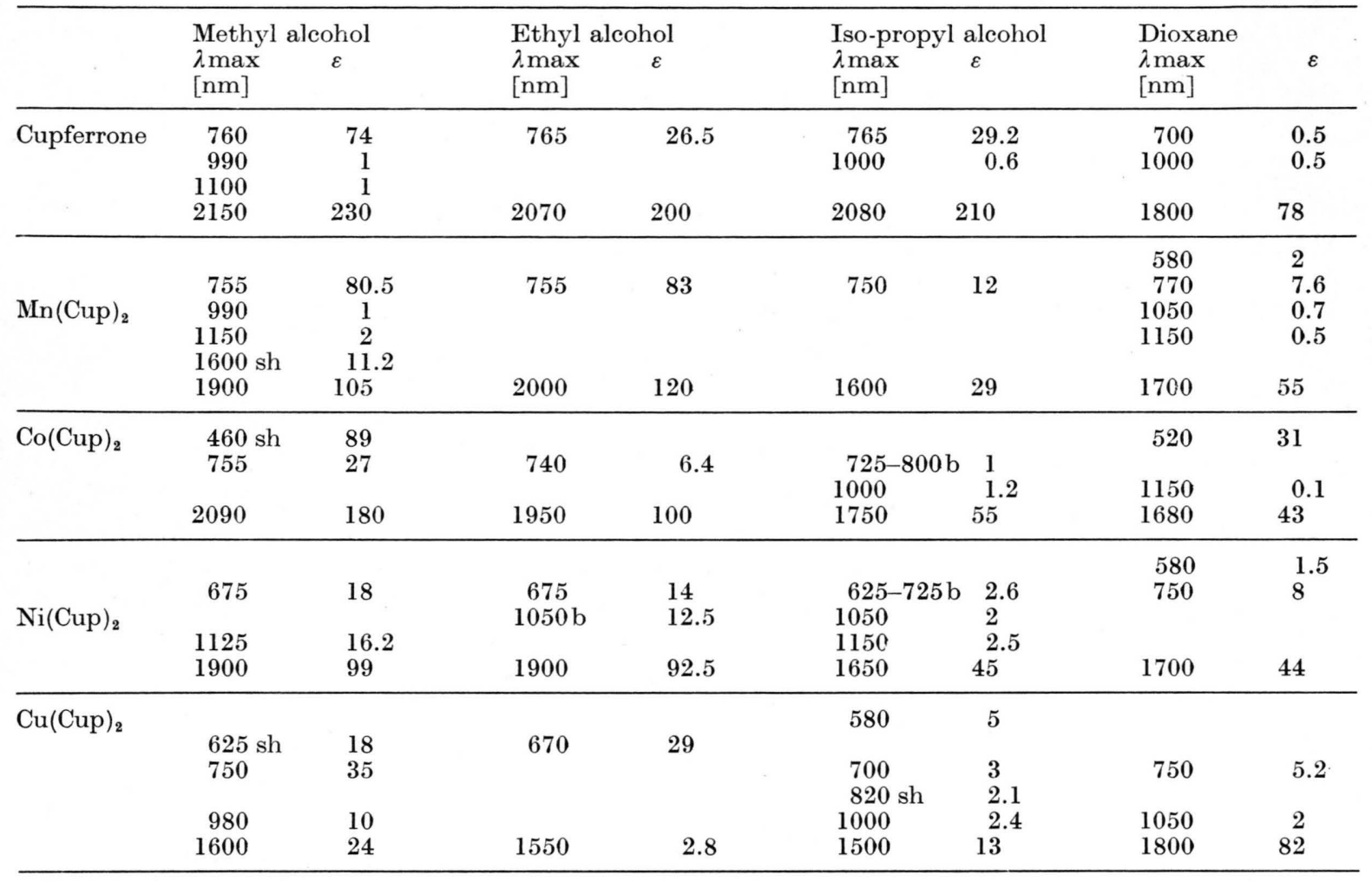

$\mathrm{sh}=$ shoulder $; \mathrm{b}=$ broad.

The other intense band observed near $1900 \mathrm{~nm}$ shows a strong solvent effect, the absorption band maximum shifts towards shorter wavelengths on decreasing solvent polarity. This band may be assigned as an overtone of the $\mathrm{N}-\mathrm{H}$ stretching vibrations of the ammonium ion which has a strong band near $3170 \mathrm{~cm}^{-1}$ in the solid state IR spectrum ${ }^{3}$.

\section{Electronic spectra of divalent transition cupferrates}

The visible and near IR absorption spectra of Mn, Co, Ni, and Cu cupferrates are given in Figs. 1-4. Some of the absorption bands observed are similar to that of the ammonium cupferron. However, a slight shift of the observed bands is found for metal complexes. Such behaviour could be explained on the premises that by replacing the ammonium group by relatively stronger electron acceptor metal cations, electrons will be shifted from benzene ring through the oxygen ligand. Thus, with a removal of electrons from the benzene ring, the energy required to remove an electron to higher orbitals will increase with a subsequent decrease in position of the band wavelength.

Manganese cupferrate; IR measurements reported ${ }^{3}$ suggest a tetrahedral structure for the cupferrate complexes investigated. High spin $3 \mathrm{~d}^{5}$ complexes have only one spin sextet, the ground state; all excited d-manifold states are either quartets or doublets. All transitions between states are thus formally spin forbidden and are only observed as the result of spin-orbit coupling between the excited quartets and either higher lying sextet states (non-d-manifold: e.g. charge fransfer) and/or the ground sextet state ${ }^{7}$. The manganous ion has four excited terms within the $3 \mathrm{~d}^{5}$ configuration: ${ }^{4} \mathrm{G},{ }^{4} \mathrm{P}$, ${ }^{4} \mathrm{D}$ and ${ }^{4} \mathrm{~F}$. Following Tanabe and Sugano ${ }^{8}$ the crystal field strength in tetrahedral manganese complexes does not enough to force the change of the ground state from ${ }^{6} \mathrm{~A}_{1}(\mathrm{~S})$ to ${ }^{2} \mathrm{~T}_{2}\left({ }^{2} \mathrm{I}\right)$, therefore, the absorption band observed in dioxane at $580 \mathrm{~nm}$, which fades in polar solvents, could be assigned to the transition ${ }^{6} \mathrm{~A}_{1}(\mathrm{~S}) \rightarrow{ }^{4} \mathrm{~T}_{1}\left({ }^{1} \mathrm{G}\right)$. The $755 \mathrm{~nm}$ band 
shows a shift of $\approx 5 \mathrm{~nm}$ in methyl alcohol and $70 \mathrm{~nm}$ in dioxane with respect to that of cupferron. Moreover, two weak bands were observed near $1000 \mathrm{~nm}$ and $1150 \mathrm{~nm}$ in methyl alcohol and dioxane solutions. The strong band appeared at $1800 \pm 200 \mathrm{~nm}$ shows strong solvent effect, a band shift $\approx 200 \mathrm{~nm}$ was observed when solvent changes from methyl alcohol to dioxane.

Cobalt cupferrate: High spin $3 \mathrm{~d}^{7}$ complexes have a spin quartet ground state ${ }^{4} \mathrm{~A}_{2}(\mathrm{~F})$; all excited d-manifold states are either quartets or doublets. In the absorption spectrum of cobalt cupferrate two strong bands were observed near $460 \mathrm{~nm}, 1800 \mathrm{~nm}$ and two weak bands near $740 \mathrm{~nm}$ and $1000 \mathrm{~nm}$. The Tanabe-Sugano diagram ${ }^{8}$ predicts the following spin-allowed transitions ${ }^{4} \mathrm{~A}_{2}(\mathrm{~F}) \rightarrow{ }^{4} \mathrm{~T}_{1}(\mathrm{P})$ near $740 \mathrm{~nm}$ and ${ }^{4} \mathrm{~A}_{2}(\mathrm{~F}) \rightarrow{ }^{4} \mathrm{~T}_{1}(\mathrm{~F})$ at $1800 \mathrm{~nm}$. However, a 755 band appears also in the spectrum of cupferron and therefore, the $740 \mathrm{~nm}$ band of nickel cupferrate is mainly attributed to the $n \rightarrow \pi^{*}$ transition. The broad band around $740 \mathrm{~nm}$ in polar solvents and $520 \mathrm{~nm}$ in dioxane could be assigned to the transition ${ }^{4} \mathrm{~A}_{2}(\mathrm{~F}) \rightarrow{ }^{2} \mathrm{~T}_{2}(\mathrm{G})$ expected at $440 \mathrm{~nm}$ and ${ }^{4} \mathrm{~A}_{2}(\mathrm{~F}) \rightarrow{ }^{2} \mathrm{~T}_{1}(\mathrm{G})$ expected at $490 \mathrm{~nm}$ influenced by the solvent polarity and hydrogen bonding.

Nickel cupferrate: $3 \mathrm{~d}^{8}$ complexes have a spin triplet state ${ }^{3} \mathrm{~T}_{1}(\mathrm{~F})$; all excited d-manifold states are triplets or singlets. Four absorption bands were observed in the spectrum of nickel cupferrate at $580 \mathrm{~nm}, 700 \mathrm{~nm}, 1100 \mathrm{~nm}$ and $1775 \pm 125 \mathrm{~nm}$. The $1775 \mathrm{~nm}$ absorption band shows a strong solvent effect, the band maximum moves to shorter wavelengths on decreasing solvent polarity. There-

${ }^{1}$ M. Piskorz and T. Urbanski, Bull. Aead. Polon. Sci. Ser. Sci. Chem. 11, 597 [1963].

2 T. Yoshimura, C. Miyake, and S. Imoto, Bull. Chem. Soc. Jap. 45, No 5, 1424 [1972].

3 A. H. Abou El Ela, F. M. Abd El Kerim, H. H. AfrFi, and H. F. ALI, Z. Naturforsch. 28b, 610 [1973].

4 A. H. Abou El Ela and H. H. Afifi, Z. Naturforsch. 29 a, 719 [1974].

5 K. Nakamoto and R. E. Pundle, J. Amer. Chem. Soc. 78, 1113 [1956]. fore, polar solvents give rise to a decrease in the excitation energy of the $1775 \mathrm{~nm}$ band. The Tanabe-Sugano diagram ${ }^{8}$ for tetrahedral nickel complexes shows that there are three spin allowed transitions from ${ }^{3} \mathrm{~T}_{1}(\mathrm{~F})$ ground state. The bands observed near $528 \mathrm{~nm}$ and $625 \mathrm{~nm}$ could be ascribed to the single transition ${ }^{3} \mathrm{~T}_{1}(\mathrm{~F}) \rightarrow{ }^{3} \mathrm{~T}_{1}(\mathrm{P})$ and the band observed at $1775 \mathrm{~nm}$ could be assigned to the ${ }^{3} \mathrm{~T}_{1}(\mathrm{~F}) \rightarrow{ }^{3} \mathrm{~A}_{2}(\mathrm{~F})$ transition.

Copper cupferrate: One intense band at $1675 \pm$ $125 \mathrm{~nm}$ and four weak bands at $580 \mathrm{~nm}, 647 \mathrm{~nm}$, $720 \mathrm{~nm}$ and $820 \mathrm{~nm}$ were observed in the absorption spectrum of copper cupferrate. Copper complexes have a spin doublet ground state ${ }^{2} \mathrm{E}$. Ligand field theory ${ }^{9}$ predicts only one transition between the doublet states of $\mathrm{Cu}^{2+}$ ion in tetrahedral field ${ }^{2} \mathrm{~T}_{2}(\mathrm{D}) \rightarrow{ }^{2} \mathrm{E}$ at about $6000 \mathrm{~cm}^{-1}$ in the near IR region. Therefore, the absorption band observed at $1675 \pm 125 \mathrm{~nm}$ could be ascribed to this transition. This band shows a shift to lower wavelengths on increasing solvent polarity, in opposite to other cupferrates. A band shift of $200 \mathrm{~nm}$ was observed when the solvent changes from methyl alcohol to dioxane. This shift shows that polar solvents increase the excitation energy of the ${ }^{2} \mathrm{~T}_{2}(\mathrm{D}) \rightarrow^{2} \mathrm{E}$ transition in copper cupferrate.

Since copper is a very strong electron acceptor, other bands observed at $580 \mathrm{~nm}, 645 \mathrm{~nm}, 720 \mathrm{~nm}$ and $820 \mathrm{~nm}$ could be considered as charge transfer bands ${ }^{10}$ related to the electron donating and accepting properties of the ligand and the metal ion and could be assigned as transitions between the molecular orbitals of the complex ion.

${ }^{6}$ R. N. Haszeldine and J. Jander, J. Chem. Soc. 1954, 691 .

7 P. Day and C. K. Jørgensen, J. Chem. Soc. Supl. 2, 6226 [1964].

8 Y. Tanabe and S. Sugano, J. Chem. Soc. Jap. 9, 753 [1954].

${ }^{9}$ B. N. Figgis, Introduction to Ligand Fields, Interscience Publication, New York 1966.

10 C. J. Ballhausen and A. D. Liehr, J. Mol. Spectrosc. 2, 342 [1958], ibid. 4, 190 [1960]. 